\title{
Strategic value creation in a supply chain
}

\begin{abstract}
This chapter is designed to give the readers a concise understanding of supply chain strategies and the process involved in its formation. It is a background study on the changing role of supply chain in gaining competitive advantage for the firm. The chapter discusses on traceability and integration along a supply chain, its inception and the advantages to the corporate world through its implementation. The chapter focuses on the topic of value creation in a supply chain through strategic management decisions like vertical and horizontal integration. The value chain analysis model for competitive advantage is covered in this chapter. A discussion on the differences between vertical and horizontal integration systems and the best strategic decision among them is provided. The concepts of sustainable supply chain integration, traceability, and the limitations to their implementation have also been discussed. The best examples on practitioners of supply chain strategy and integration are provided along the chapter.
\end{abstract}

